\title{
T3P as an efficient cyclodehydration reagent for the one-pot synthesis of 2-amino-1,3,4-oxadiazoles
}

\author{
ANDIVELU ILANGOVAN ${ }^{\mathrm{a}, *}$, SHANMUGASUNDAR SARAVANAKUMAR ${ }^{\mathrm{a}, \mathrm{b}}$ and \\ SIDDAPPA UMESH ${ }^{\mathrm{b}}$ \\ ${ }^{\text {a}}$ School of Chemistry, Bharathidasan University, Tiruchirappalli 620024, India \\ byngene International Ltd., Bangalore 560 099, India \\ e-mail: ilangovanbdu@yahoo.com
}

MS received 10 August 2014; revised 20 January 2015; accepted 30 April 2015

\begin{abstract}
A scalable and environmentally friendly one-pot method for the synthesis of 2-amino-1,3,4oxadiazoles from acylhydrazides and isocyanates has been achieved with propane phosponic anhydride (T3P) acting as cyclodehydrating reagent.
\end{abstract}

Keywords. Cyclizations; 2-amino-1,3,4-oxadiazoles; propane phosponic anhydride; heterocycles; one-pot synthesis

\section{Introduction}

1,3,4-Oxadiazoles constitute the core structure of a number of pharmacologically and biologically important compounds. ${ }^{1}$ Drugs such as tiodazosin, nesapidil, furamizole and raltegravir and Zibotentan, which is in the late clinical development stage, have the heterocyclic oxadiazole nucleus. Also, a large number of patent applications containing the oxadiazole nucleus substantiate its importance (figure 1). ${ }^{5,6 a}$ Further, the utility of the sub-class 2-amino-1,3,4-oxadiazoles was demonstrated through numerous biological activities such as anti-microbial, ${ }^{2 \mathrm{a}}$ anti-convulsant, ${ }^{2 \mathrm{~b}}$ anti-cancer, ${ }^{2 \mathrm{c}}$ anti-mitotic, ${ }^{2 \mathrm{~d}}$ and muscle relaxants. ${ }^{2 \mathrm{e}}$ In addition, they find application in agricultural chemistry as active scaffolds $^{3 \mathrm{a}}$ and in material science as photosensitizers. ${ }^{3 \mathrm{~b}}$

An elaborate survey of the literature revealed that the methods used for the preparation of 2-amino-1,3,4oxadiazoles can be classified into a few categories. The widely used approach is cyclodesulfurization of acyl thiosemicarbazides and a number of reagents such as carodiimides, ${ }^{4}$ tosyl chloride/pyridine, ${ }^{5}$ 2-iodoxybenzoic acid (IBX), ${ }^{6 \mathrm{a}} \mathrm{I}_{2} / \mathrm{NaOH}^{6 \mathrm{~b}}$ and mercury salts ${ }^{7}$ have been employed for this purpose. These reagents promote the cyclization by selectively activating the sulphur moiety. Carbodiimides acted as $\mathrm{H}_{2} \mathrm{~S}$ scavengers while iodine reagents shifted the equilibrium to the right side by precipitating elemental sulphur. This method has been successfully exploited in solid phase synthesis

*For correspondence with the aid of polymer supported reagents. ${ }^{8}$ The problems associated with these methods are the use of toxic reagents and the formation of significant byproducts such as 1,3,4-thiadiazoles.

The next important approach is cyclodehydration of acylsemicarbazides. Although this method appeared to be most clear-cut, harsh reagents such as $\mathrm{H}_{2} \mathrm{SO}_{4},{ }^{9}$ $\mathrm{POCl}_{3},{ }^{9 \mathrm{~b}} \mathrm{SOCl}_{2}{ }^{9 \mathrm{~b}}$ and $\mathrm{PPh}_{3} / \mathrm{CCl}_{4}{ }^{10}$ were used. Burgess reagent, ${ }^{11}$ polymer supported $\mathrm{N}, \mathrm{N}$ '-dicyclohexylcarbodiimide (DCC) ${ }^{12}$ and polymer supported phosphazine base $^{12}$ effected this conversion only under microwave irradiation. It seems this method is less preferred as it employed unfavorable reagents and suited only for solid phase synthesis. In line with the cyclodesulfurization approach, selenosemicarbazides were converted into 2-amino-1,3,4-oxadiazoles without any deselenizing reagent. ${ }^{15}$ The other important approach includes $\mathrm{S}_{\mathrm{N}} \mathrm{Ar}$ substitution of oxadiazol-2-ones by activation using the phosphonium reagent (benzotriazol-1-yloxy)tris(dimethylamino)phosphonium hexafluorophosphate (BOP). ${ }^{13}$

A variety of peptide coupling reagents such as $\mathrm{DCC}^{12}$, 1-ethyl-3-(3-dimethylaminopropyl)carbodiimide (EDCI), ${ }^{4}$ O-(benzotriazol-1-yl)-N,N, $\mathrm{N}^{\prime}, \mathrm{N}^{\prime}$-tetramethyluronium tetrafluoroborate (TBTU) ${ }^{14}$ have been engaged as the cyclodesufurizers, however their role in cyclodehydration is very limited and only an example of using DCC under microwave irradiation is known. ${ }^{12}$ The disadvantages of using coupling reagents are the need for large excess (at least 3 equiv.) of reagents, purification to remove residues of some of the coupling reagents, difficulty in the availability of resin-bound coupling agents and lower yields. Thus, identification of an efficient 


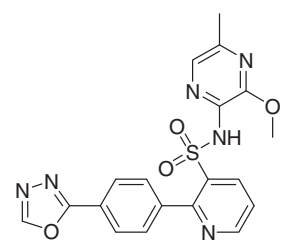

Zibotentan (In late clinical development as anti-cancer agent)

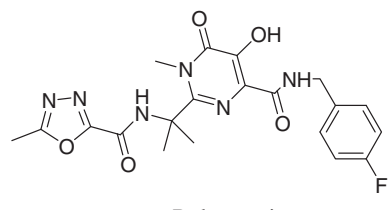
Raltegravir
(Anti-retroviral agent)

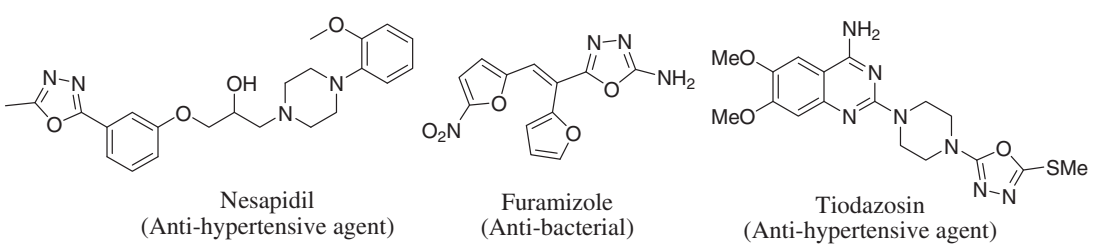

Figure 1. Important bioactive oxadiazoles.

coupling reagent for cyclodehydration of acyl semicarbazides is still a challenge (figure 2).

Propane phosponic anhydride (T3P) is a preferred peptide coupling reagent due to the advantages such as low toxicity, broad functional group tolerance, low epimerization and solubility of by-products in water. ${ }^{16}$ In the past, T3P has been used for the synthesis of heterocycles such as indoles, ${ }^{17 \mathrm{a}}$ quinolines, ${ }^{17 \mathrm{~b}}$ 1,3-benzazoles, ${ }^{17 \mathrm{c}}$ thieno [2,3-d]pyrimidin-4-ol ${ }^{17 \mathrm{~d}}$ and oxadiaoles ${ }^{17 \mathrm{e}}$ besides used in various other transformations such as carboxylic acids and amides to nitriles, ${ }^{18 \mathrm{a}}$ acylations, ${ }^{18 \mathrm{~b}}$ and Perkin rearrangement ${ }^{18 \mathrm{c}}$ apart from peptide coupling. Considering various important applications of 2amino-1,3,4-oxadiazoles, developing a new and mild method overcoming the aforesaid problems, would be highly desirable. In this direction, we examined different peptide coupling reagents for the cyclodehydration reaction of acylsemicarbazides to get 2-amino-1,3,4oxadiazoles.

\section{Experimental}

\subsection{Materials and Instrumentation}

Proton $\left({ }^{1} \mathrm{H}\right.$ NMR $)$ and carbon $\left({ }^{13} \mathrm{C}\right.$ NMR $)$ nuclear magnetic resonance spectra were recorded on Bruker 300 $\& 400 \mathrm{MHz}$ instruments. Chemical shifts are reported in ppm $(\delta)$ relative to internal standard tetramethylsilane (TMS, $\delta 0.00 \mathrm{ppm}$ ). Carbon chemical shifts are reported in ppm with respect to solvent resonance as the internal standard $\left(\mathrm{CDCl}_{3}\right.$ at $77.0 \mathrm{ppm}$ and DMSO$d_{6}$ at $\left.39.5 \mathrm{ppm}\right)$. Data are reported as follows: chemical shift (multiplicity [singlet (s), doublet (d), triplet (t), quartet (q), pentet (p), multiplet (m), broad (br)], coupling constants [Hz], integration). All the NMR spectra were acquired at ambient temperature. Infrared (FT-IR) spectra were recorded on a Perkin-Elmer spectrometer. Analytical thin-layer chromatography (TLC) was performed using Silica Gel $60 \AA$ F254 pre-coated plates

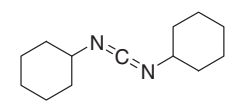

N,N'-Dicyclohexylcarbodiimide<smiles>CCN=C=NCCCN(C)C</smiles>

1-Ethyl-3-(3-dimethylaminopropyl)carbodiimide

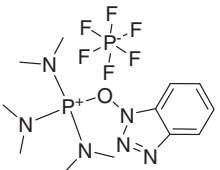

(Benzotriazol-1-yloxy)tris(dimethylamino)phosphonium hexafluorophosphate O-(Benzotriazol-1-yl)-N,N,N',N'-tetramethyluronium
tetrafluoroborate

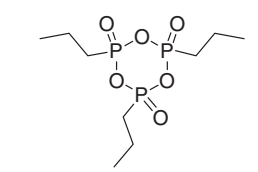

Propane phosponic anhydride

Figure 2. Few cyclodehydrating agents. 
(0.25 mm thickness). Visualization was accomplished by irradiation with a UV lamp and staining with $\mathrm{I}_{2}$ on silica gel. Flash column chromatography was performed using Silica Gel 60-120 ̊ (32-63 micron). The elemental analysis was done with vario MICRO V1.3.2 Elemental Analyser system, $\mathrm{GmbH}$ instruments. Reactions that required atmosphere and moisture control were carried out in argon atmosphere employing flame-dried glassware. All solvents and chemicals were purchased from commercial sources.

\subsection{General method: Typical experimental procedure} for the preparation of 2-amino-1,3,4-oxadiazoles (4)

Hydrazide 1 ( $0.5 \mathrm{mmol})$ was added slowly to a solution of isocyanate $2(0.5 \mathrm{mmol})$ in toluene $(3 \mathrm{~mL})$ at room temperature and the mixture was stirred for $30 \mathrm{~min}$. Completion of the reaction was checked by TLC, then T3P (1.5 mmol, 50\% in EtOAc) was added under stirring. The resulting suspension was heated at $100^{\circ} \mathrm{C}$ for 2-4 hours. The clear solution was cooled to ambient temperature and carefully quenched with $10 \% \mathrm{NaHCO}_{3}$ solution. The organic layer was separated, washed with water $(2 \times 2 \mathrm{~mL})$, brine $(2 \mathrm{~mL})$, dried over $\mathrm{Na}_{2} \mathrm{SO}_{4}$ and evaporated under reduced pressure to get the crude product which was purified by column chromatography.

\section{Results and Discussion}

5-(4-Methoxybenzoyl)-N-(p-tolyl)hydrazine-1-carboxamide 3a, prepared from 4-methoxybenzohydrazide, was taken as the model compound for the screening experiments with different coupling reagents for the cyclodehydration reaction. The reaction was carried out at $100^{\circ} \mathrm{C}$ in different solvents and the results are summarized in table 1.

While BOP and DPPA gave 5\% and 3\% of the desired product respectively, other reagents such as CDI, EDCI, TBTU and Mukaiyama reagent failed to cause any conversion. However, T3P, a mild water scavenger and a low epimerization coupling reagent, delivered the product $4 a$ in $60 \%$ yield in acetonitrile as the solvent (table 1, entry 8 ). The best result was obtained with 1.5 equiv. of T3P in toluene at $100^{\circ} \mathrm{C}$ (table 1 , entry $11,88 \%)$. Other solvents such as dioxane, DMF, acetonitrile only lowered the yield. Interestingly, increasing the quantity of T3P lowered the yield (table 1, entry 14). When the reaction was carried out at reflux temperature (table 1, entry 12), there was no change in the yield. This result shows that the maximum yield can be obtained with $100^{\circ} \mathrm{C}$ itself and also there was no reaction in the absence of T3P (table 1 , entry 15 ). The results clearly demonstrated that T3P played a vital role in the reaction and found to be the most suitable

Table 1. Optimisation of peptide coupling reagents in the synthesis of 2-amino-1,3,4-oxadiazoles.

\begin{tabular}{lcccccc} 
& & & & \\
\hline
\end{tabular}

${ }^{a}$ with 3 equiv. of triethylamine; ${ }^{b}$ isolated yield: $\mathrm{NR}=$ no reaction. 
reagent among the coupling reagents for the conversion of semicarbazides to 2-amino-1,3,4-oxadiazoles.

Having the optimized conditions in hand, next we wanted to test the one-pot synthesis of 2-amino-1,3,4oxadiazoles. Since the acylsemicarbazides are formed rapidly in almost pure form from acylhydrazides and isocyanates, its isolation is not necessary and the crude suspension itself could be taken for the cyclodehydration. This hypothesis was tested by carrying out an experiment with equimolar amounts of hydrazide 1a and isocyanate 2a under the optimized reaction conditions. Gratifyingly, the reaction produced the same yield as that of the isolated acylsemicarbazide experiment. This result prompted us to test the scope of the

Table 2. One-pot synthesis of 2-amino-1, 3, 4-oxadiazoles ${ }^{\mathrm{a}}$.

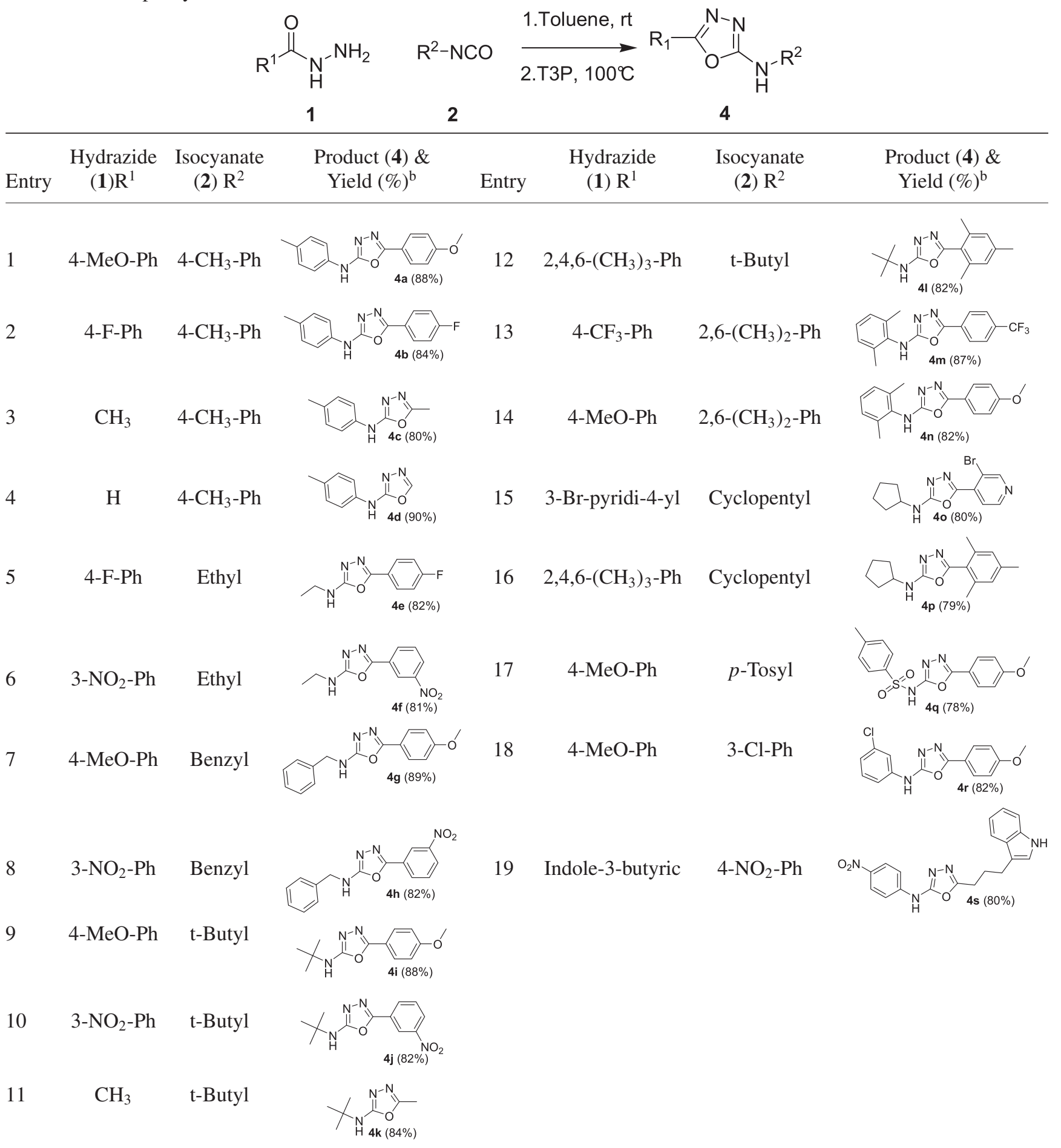

\footnotetext{
${ }^{\mathrm{a}}$ Reaction conditions: Acylhydrazide (1 eq), isocyanate $(1 \mathrm{eq})$, Toluene $(2 \mathrm{~mL}), \mathrm{T} 3 \mathrm{P}(1.5 \mathrm{eq}), 100^{\circ} \mathrm{C}, 2-3 \mathrm{~h} ;{ }^{\mathrm{b}}$ Isolated yield.
} 
one pot methodology with a range of substrates and the results are presented in table 2.

All the products were obtained in good to excellent yield with electron donating hydrazides giving slightly higher yields than the electron withdrawing counterparts. Study of the steric effect showed that hindered substrates (table 2, entry 12 and 16) reacted slowly even though good yields were obtained in such cases. The mild conditions are tolerable to different heterocyclic ring systems including isonicotinic and indole rings (table 2, entry 15 and 19). The steric factor played a negligent role with respect to isocyanates since primary, secondary and tertiary isocyanates produced similar yields and similar reactivity.

\section{Conclusion}

We have described an efficient procedure for the preparation of 2-amino-1,3,4-oxadiazoles from acylhydrazides and isocyanates under one-pot conditions using T3P. Unlike other coupling reagents, T3P has effectively activated one of the oxygens in acylsemicarbazides to produce the cyclic compound. The conditions are simple, mild, non-toxic, environmentally benign, scalable and thus it is one of the robust methods available for the preparation of 2-amino-1,3,4-oxadiazoles.

\section{Supplementary Information}

All additional information pertaining to characterization of all new compounds are given the supplementary information along with copies of ${ }^{1} \mathrm{H}$ and ${ }^{13} \mathrm{C}$ spectra and are available at www.ias.ac.in/chemsci.

\section{Acknowledgements}

SS \& SU are thankful to Dr. G.Manickam for his valuable advice and Syngene International Ltd. for providing facilities to carry out the research work.

\section{References}

1. Bostrom J, Hogner A, Linas A, Wellner E and Plowright A 2012 J. Med. Chem. 551817

2. (a) Nofal Z M, Fahmy H H and Mohamed H S 2002 Arch.Pharm. Res. 25 28; (b) Chapleo C B, Myers M, Saville J F, Smith A C B, Stilling M R, Tulloch I F, Walter D S and Welbourn A P 1986 J. Med. Chem. 29
2273; (c) Kiselyov A M M, Oprea T, Lemcke H, Weiss D G, Ikizalp N N, Kuznetsov S A and Semenov V V 2010 Eur. J. Med. Chem. 45 1683; (d) Yale H L and Losee K 1966 J. Med. Chem. 9 478; (e) Ghirian D, Schwatz I and Simiti I 1974 Farmacia 22141

3. (a) Zou X J, Lai L H, Jin G Y and Zhang Z X $2002 \mathrm{~J}$. Agric. Food. Chem. 50 3757; (b) Chudgar N K, Shah S N and Vora R A 1989 Mol. Cryst. Lig. Cryst. 172 51

4. Chekler E L P, Elokdah H M and Butera J 2008 Tetrahedron Lett. 496709

5. Dolman S J, Gosselin F, Shea P D and Davies I W 2006 J. Org. Chem. 719548

6. (a) Chaudhari P S, Pathare S P and Akamanchi K G 2012 J. Org. Chem. 77 3716; (b) Amir M and Kumar S 2004 Ind. J. Heterocycl. Chem. 1451

7. (a) Gavrilyuk J I, Lough A J and Batey R A 2008 Tetrahedron Lett. 49 4746; (b) Rostom S A, Shalaby M A and Demellawy E M 2003 Eur. J. Med. Chem. 38 959; (c) Zhang X, Xiao Y and Qian X 2008 Angew. Chem.Intl. Ed. 478025

8. (a) Kilburn J P, Lau J and Jones, R C F 2001 Tetrahedron Lett. 42 2583; (b) Severinsen R, Kilburn J P and Lau J F 2005 Tetrahedron $\mathbf{6 1} 5565$

9. (a) Sharma S, Srivastava V K and Kumar A 2002 Eur. J. Med. Chem. 37 689. (b) Hamad A S S and Hashem A 2002 J. Heterocycl. Chem. 391325

10. (a) Appel R, Kleinstuck R and Ziehn K D 1971 Chem. Ber. 104 1335; (b) Dumciute J, Martynaitis V, Holzer W, Manelinckx S, Kimpe N D and Sackus A S 2006 Tetrahedron 623309

11. Brain C T, Paul J M, Loong Y and Oakley P J 1999 Tetrahedron Lett. 403275

12. Baxendale I R, Ley S V and Martinelli M M 2005 Tetrahedron 615323

13. Levins C G and Wan Z K 2008 Org. Lett. 101755

14. Maghari S, Ramezanpour S, Darviche F, Balalaie S, Rominger F and Bijanzadeh H R 2013 Tetrahedron 69 2075

15. Xie Y, Liu J, Yang P, Shi X and Li J 2011 Tetrahedron 675369

16. (a) Esher R and Buning P 1986 Angew. Chem. Int. Ed. Engl. 25 277; (b) Klose J, Bienert M, Mollenkop, C, Wehle D, Zhang, C -W, Carpino L A and Henklein P 1999 Chem. Commun. 1847

17. (a) Desroses M, Wieckowski M and Odell L R 2011 Tetrahedron Lett. 52 4417; (b) Augustine J K, Bombrun A and Venkatachaliah S 2011 Tetrahedron Lett. 52 6814; (c) Wen X, Bakali J E, Deprez-Poulain R and Deprez B 2012 Tetrahedron Lett. 53 2440; (d) Poojari S P, Naik P and Krishnamurthy G 2012 Tetrahedron Lett. 53 4639; (e) Augustine J K, Vairaperumal V, Narasimhan S, Alagarsamy P and Radhakrishnan A 2009 Tetrahedron 659989

18. (a) Meudt A, Scherer $\mathrm{S}$ and Nerdinger $\mathrm{S} W O$ 2005070879; (b) Hermann S DE 10063493 (2002); (c) Augustine J K, Bombrun A, Ramappa B and Boodappa C 2012 Tetrahedron Lett. $\mathbf{5 3} 4422$ 